\title{
Comportamento individual e coletivo no enfretamento à Covid-19 numa cidade de pequeno porte: um relato de experiência
}

\author{
Individual and collective behavior in confronting Covid-19 in a small town: an experience report \\ Comportamiento individual y colectivo al enfrentarse al Covid-19 en un pequeño pueblo: un relato \\ de experiencia
}

Lucicleia Dias Monteiro

ORCID: https://orcid.org/0000-0002-6904-4787 Universidade Federal do Delta do Parnaíba, Brasil E-mail: lucicleiadmonteiro@gmail.com

Loredana Nilkenes Gomes da Costa

ORCID: https://orcid.org/0000-0002-4649-0282 Universidade Federal do Delta do Parnaíba, Brasil E-mail: loredananilkenes@gmail.com Rodrigo Elisio de Sá

ORCID: https://orcid.org/0000-0002-1492-3995 Universidade Federal do Delta do Parnaíba, Brasil E-mail: rodrigosa238@gmail.com

Lenilson do Nascimento Melo Junior ORCID: https://orcid.org/0000-0001-8258-3753 Universidade Federal do Delta do Parnaíba, Brasil E-mail: jrdemelo01@gmail.com Lucas Florencia da Silva

ORCID: https://orcid.org/0000-0002-7575-3643 Universidade Federal do Delta do Parnaíba, Brasil E-mail: lucasflorenci@ gmail.com Fabrício dos Santos Machado

ORCID: https://orcid.org/0000-0003-1637-5934 Universidade Federal do Delta do Parnaíba, Brasil E-mail: fabricio.machado10@live.com

Gabrielle Costa Sousa

ORCID: https://orcid.org/0000-0001-8496-3477 Universidade Federal do Delta do Parnaíba, Brasil E-mail: gabygabryelle19@hotmail.com

Annarelly Morais Mendes

ORCID: https://orcid.org/0000-0002-4367-8888

Universidade Estadual do Maranhão, Brasil E-mail: annarellymorais1@gmail.com Isa Maraya Pereira Monteiro

ORCID: https://orcid.org/0000-0002-3581-0017 Universidade Federal do Delta do Parnaíba, Brasil E-mail: marayabiomed@ hotmail.com

Myllena Rayanne Mendes Pereira ORCID: https://orcid.org/0000-0001-5953-0573 Universidade Federal do Delta do Parnaíba, Brasil E-mail: myllenaray98@gmail.com

Maria Rikelly Frota Aguiar

ORCID: https://orcid.org/0000-0001-5041-8753

Universidade Federal do Delta do Parnaíba, Brasil E-mail: mariarikellyurca@hotmail.com

\begin{abstract}
Resumo
A pandemia da Covid-19 afetou fortemente o Brasil desde o ano de 2020, sobretudo as pequenas cidades devida a falta de infraestrutura para suprir as necessidades da população afetados com a doença. O trabalho consiste em um relato de experiência sobre um Projeto, fomentado pela Universidade Federal do Delta do Parnaíba, levantando estratégias de ação para o combate ao novo coronavírus no município de pequeno porte, vizinho a instituição. Proporcionando informações a locais onde o acesso a elas são mais escassos, além disso, tendo em vista a condição de
\end{abstract}


vulnerabilidade social encontrada em algumas localidades da cidade, foram arrecadados e distribuídos máscaras de tecido, sabão e sabonete para prevenção e conscientização de indivíduos mais humildes. Dessa forma, foi possível analisar o cenário no enfretamento ao vírus, retratar os principais fatos e como a condição social a falta de informação pode impactar negativamente esse controle.

Palavras-chave: Condição social; Covid-19; Brasil.

\begin{abstract}
The Covid-19 pandemic has strongly affected Brazil since 2020, especially as small cities due to the lack of infrastructure to meet the needs of the population affected by the disease. The work consists of an experience report on a Project, promoted by the Federal University of Delta do Parnaíba, raising action strategies to combat the new coronavirus in the small town, neighboring the institution. Providing information to places where access to them is scarcer, in addition, given the condition of social vulnerability found in some parts of the city, cloth masks, soap and soap were collected and distributed for prevention and awareness of the most humble. Thus, it was possible to analyze the scenario in the fight against the virus, portray the main facts and how the social condition and lack of information can negatively impact this control.
\end{abstract}

Keywords: Social conditions; Covid-19; Brazil.

\title{
Resumen
}

La pandemia Covid-19 ha afectado fuertemente a Brasil desde 2020, especialmente como ciudades pequeñas debido a la falta de infraestructura para satisfacer las necesidades de la población afectada por la enfermedad. El trabajo consiste en un informe de experiencia sobre un Proyecto, impulsado por la Universidad Federal del Delta do Parnaíba, planteando estrategias de acción para combatir el nuevo coronavirus en la pequeña localidad, vecina a la institución. Brindando información a los lugares donde el acceso a ellos es más escaso, además, dada la condición de vulnerabilidad social que se encuentra en algunos puntos de la ciudad, se recolectaron y distribuyeron máscaras de tela, jabón y jabón para la prevención y concientización de los más humildes. Así, fue posible analizar el escenario en la lucha contra el virus, retratar los principales hechos y cómo la condición social y la falta de información pueden impactar negativamente este control.

Palabras clave: Condición social; Covid-19; Brasil.

\section{Introdução}

No início de 2020, em Wuhan, na China, surgiu indivíduos infectados com um vírus de uma família conhecida, porém com características diferentes que posteriormente se tornou uma pandemia, afetando mais de 188 países (Senhoras, 2020). Segundo informações disponibilizadas pela Organização Mundial da Saúde (OMS), o Sars-Cov-2, como foi chamado o novo membro da família dos Corona vírus (Chan, 2013), era responsável por causar às pessoas a Covid-19 (Coronavirus Disease 2019), doença que assolou e ainda assola a população mundial. A Covid-19 é caracterizada por provocar, em suas vítimas, sintomas típicos de uma gripe, febre, tosse e cansaço. No entanto, em casos graves proporciona aos pacientes, quadros de pneumonia, com presença de febre alta e dificuldade ao respirar, até a ocorrência de óbito (He, 2020).

A Organização Mundial da Saúde, até setembro de 2021, divulgou que mais de 226 milhões de pessoas são casos confirmados do novo Coronavírus e mais de 4 milhões de mortes em todo o mundo. No Brasil, segundo dados do Ministério da Saúde, são acima de 21 milhões pessoas afetadas com o vírus e o número de mortos somam cerca de 590 mil. O número de casos cresce, a cada dia, por se tratar de um vírus com alta taxa de transmissibilidade e elevada letalidade, fatores que tem despertado atenção (Silva, 2020). A grande dificuldade em enfrentar a pandemia, tem sido o descumprimento da população em relação às recomendações impostas pelas Instituições de Saúde, baixa testagem de casos suspeitos, subnotificação, escassez de Equipamentos de Proteção Individual (Nogueira, 2020) e o ritmo lento da vacinação em massa. Dessa forma, munir a sociedade com informações seguras e para todos os estratos sociais, tem sido uma das estratégias mais eficazes na luta contra o novo Coronavírus.

Apesar dos avanços, o Sars-Cov-2 ainda possui algumas incógnitas a serem desvendadas. A propagação do novo Coronavírus tem causado grande impacto nos aspectos econômico, social e saúde, de todos os países atingidos. Dessa forma, a necessidade de conhecer características e comportamentos referentes à doença e aos infectados, colabora para que os efeitos da 
pandemia sejam diminuídos. No Brasil, a dificuldade em controlar a pandemia tem sido causada por diversos motivos, dentre eles, é apontada a subnotificação que está diretamente ligada com a falta de ampla testagem e se refere a uma situação em que o número de casos é diferente do valor real de infectados (Nogueira, 2020). A condição que favorece esse cenário, se dá pela dificuldade de realização de testes, por pessoas assintomáticas ou com sintomas leves da doença, dessa forma, a chance de propagação do vírus se torna maior (Nogueira, 2020). A desinformação também tem colaborado com o avanço da pandemia no país. A disseminação de fake news, devido a habilidade dos profissionais em produzir essas afirmações de cunho duvidoso, levam os indivíduos a não checarem informações e compartilharem as mensagens falsas, acarretando desinformação e medo, atrapalhando, dessa forma, o trabalho dos órgãos envolvidos no controle desse novo vírus (Sousa Junior, 2020).

De acordo com o Monitora Covid 19- Sistema de Informação para Monitoramento da Pandemia do Coronavírus (Covid-19), o perfil de disseminação do Sars- Cov-2 foi se modificado gradativamente, se deslocando das grandes metrópoles para regiões interioranas do país, gerando preocupação, tendo em vista que algumas cidades não dispõem de infraestruturas necessárias para oferecer a pacientes com Covid- 19, em estado grave. Por isso a necessidade de conter o vírus, em todos os lugares, sem distinção, com o objetivo de evitar a superlotação de hospitais, o colapso do sistema de saúde e o aumento no número de mortes que poderiam ser evitadas (Zanotelli, 2020).

Dado isso, o objetivo do trabalho foi de relatar a experiência obtida com o Projeto fomentado pela Universidade Federal do Delta do Parnaíba, desenvolvido por alunos da Instituição, durante a pandemia da Covid-19, com atividades executadas no município de Luís Correia-PI, além disso, apresentar os pontos mais relevantes observados na proposta.

\section{Metodologia}

O presente estudo consiste em uma relato de experiência que descreve o cenário encontrado, no desenvolvimento de um Projeto no qual recebeu suporte da Universidade Federal do Delta do Parnaíba, por meio do Edital 07/20 - Covid UFDPAR, no período de abril a dezembro de 2020, realizado por uma aluna bolsista e outros voluntários, cujo as ações ocorriam na cidade vizinha à Instituição.

Trata-se de uma análise qualitativa, a partir de métodos descritivos e observacionais. Compete ao relato de experiência uma reflexão sobre uma ação ou um conjunto delas, de forma a descrever situações vivenciadas que conduzem relevância ao meio cientifico (Estrela, 2018).

O Projeto Solidariza LC, como foi intitulado, tinha o propósito de arrecadar máscaras de tecido, sabonetes, sabão líquido ou em barra e álcool, para serem distribuídas a pessoas em situação de vulnerabilidade social que residissem no munícipio de Luís Correia-PI. Além disso, o Projeto possuía a preocupação em informar a população sobre o novo coronavírus, sanando dúvidas, combatendo fake news, educando de maneira simples e didática, para que indivíduos de qualquer escolaridade tivessem entendimento sobre o assunto.

As doações eram recebidas pela estudante bolsista, preferencialmente por meio de materiais, para que as divisões ficassem mais uniformes. A metodologia constituía-se em escolher previamente um local/bairro, ir de casa em casa, levando as doações recebidas e questionar aos moradores da residência se possuíam alguma dúvida sobre o vírus. As ações ocorriam quinzenalmente para que não houvesse uma alta exposição dos discentes. Antes das participações, os mesmos recebiam capacitação para estarem preparados as situações que pudessem acontecer, as indagações, críticas e descaso.

Além disso, também foi efetuada uma revisão literária, para obtenção do conhecimento teórico, a partir de publicações indexadas, coletados por pesquisas na base de dados Google Acadêmico e SciELo, utilizando como descritores de busca os termos: "Condição social", "Covid-19" e "Brasil", e seus respectivos correspondentes na língua inglesa. Como critérios de 
inclusão, foram considerados os artigos publicados entre os anos de 2020 a 2021, nos idiomas português e inglês, possuindo título e resumo condizente ao tema central abordado nesse artigo.

\section{Resultados e Discussão}

A seguir (Figura 1), são apresentadas as principais características encontradas nos beneficiados com o projeto, através das ações ofertadas, campanhas educativas e doações.

Figura 1. Perfil do público que recebia os alunos do Projeto.

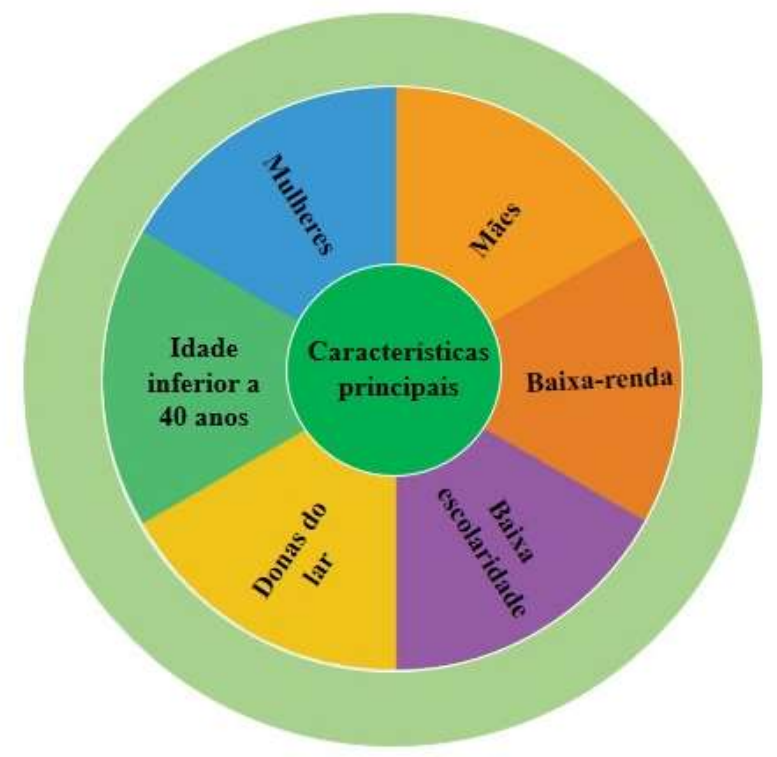

Fonte: Autoria Própria (2021).

Na figura é possível perceber um perfil interessante da população atendida. É sabido que a intenção do Projeto era amparar pessoas em situação de vulnerabilidade social, dessa forma, os bairros escolhidos para o desenvolvimento das atividades eram os mais afastados do centro da cidade, justamente, por ser mais comum presenciar esse cenário e devido a necessidade maior de proteção, desses indivíduos.

As atividades ocorriam, normalmente, no período da manhã o que denota a maior frequência de mulheres nas casas visitadas, tendo em vista que a cultura patriarcal é corriqueiro nessa região, sendo homens trabalhando fora do convívio familiar e as mulheres, cuidando dos filhos e da casa. Na recepção, essas, na maioria das vezes estavam acompanhadas de crianças, possuíam uma aparência jovem e humilde. Ao longo do diálogo era possível perceber o baixo nível de escolaridade, devido ao baixo conhecimento demonstrado e uso de um vocabulário simples e deficiente.

Em relação ao gênero, existem poucos estudos que apontem, significativamente, a diferença entre a taxa de infecção entre homens e mulheres, pois apesar do primeiro estar mais exposto ao risco do vírus, ele pode colaborar para a contaminação domiciliar (Estrela, 2020), e isso dificulta conhecer melhor essa situação. Mesmo com a implantação da conscientização para um dos membros da família sobre os cuidados necessários para evitar a Covid-19, sabe-se que faz parte da natureza masculina a resistência a prevenção e proteção à saúde (Gomes, 2007), o que torna difícil o sucesso da proposta. 
No que tange, os pontos mais observados durante os desdobramentos das tarefas impostas pelo Projeto, são elencados a seguir, na Figura 2, a fome, a recorrência de fake news, o descaso e a notoriedade do sentimento de irrelevância a respeito do novo coronavírus.

Figura 2. Características mais observação, durante a execução de tarefas do Projeto.

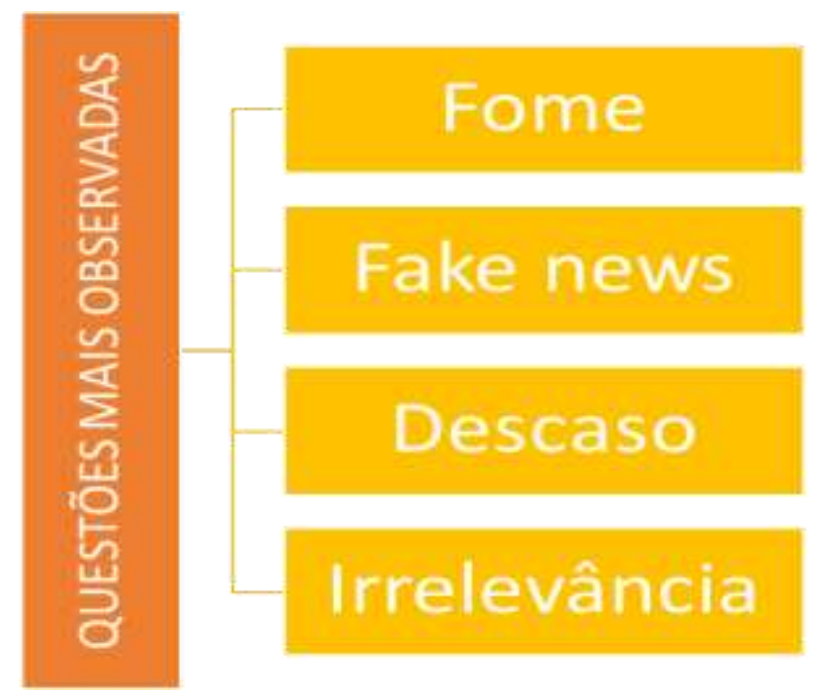

Fonte: Autoria Própria (2021).

Em algumas oportunidades, foi possível oferecer a população atendida, cestas contendo alimentos não perecíveis e juntamente com isso, eram doados máscaras de tecido, sabonete e álcool em gel. O ponto de partida era apresentar o intuito do projeto, falar um pouco sobre o vírus que tem afetado todo o mundo, desde 2020 e então fazer as doações. Nesse momento, era nítido perceber a alegria que expressavam ao receber os alimentos, em contrapartida, os meios de proteção ficavam em segundo plano. Na grande maioria das vezes, havia angustia por parte dessas pessoas pelo o que vírus estava causando, impedindo-as de ganhar o pão de cada dia, mesmo recebendo o auxílio oferecido pelo Governo Federal, não era suficiente para o sustento de toda a família, que as vezes era composta por mais de 7 pessoas.

Apesar de o Projeto adentrar locais onde o acesso à informação é mais restrito, por se tratar de populações em situação de vulnerabilidade social, os mesmos não estão imunes a fake news. Em determinada ação, a discente responsável foi questionada sobre a procedência das máscaras distribuídas, em decorrência da fake news, espalhada na área, acerca das máscaras advindas da China, o que corrobora a necessidade de esclarecimentos em todas as áreas sem distinção. Além disso, também haviam muitas indagações sobre a veracidade dos números de casos, noticiados pela mídia. Ademais, também foram consideradas as postagens realizadas na rede social Instagram que tornou-se um meio remoto de difundir informações e sanar dúvidas. Inúmeras enquetes apontaram desconhecimento e a presença forte de crenças para impedir a contaminação do novo coronavírus, como por exemplo, o uso de vitamina C, para evitar a infecção ou mesmo acreditar que por residir em uma região de clima quente, o vírus não resistir a temperatura. Na época de realização da inciativa, ainda não existiam vacinas para a Covid-19, por isso, não foram reportados comentário sobre tal conteúdo.

Outra situação muito cotidiana de ser vista, foi o descaso com o vírus. Muitos descumprimentos sobre as recomendações do Ministério da Saúde foram observadas, como a aproximação entre pessoas durante uma conversa, o grande contingente de pessoas andando nas ruas e o uso incorreto da máscara ou ausência dela. E o descaso acaba favorecendo o 
quarto aspecto mais encontrado que foi o sentido de irrelevância em relação ao combate ao vírus. Na maioria das casas que foram abrangidas pelo Projeto, as pessoas demonstraram desinteresse em pedir informações sobre o novo Coronavírus, grande parte entendia a importância de ficarem em casa, do uso de máscara e higienização frequente das mãos, todos relataram compreender a situação, em detrimento das notícias reportadas na televisão e rádio, entretanto ao mesmo tempo que falavam do mecanismo de proteção, tinha consciência sobre ele, desrespeitavam as medidas. Ao passo que, não acreditavam que se tratando de uma cidade com poucos habitantes e afastada dos grandes centros urbanos, o impacto do problema não seria severo.

Segundo o Instituto Brasileiro de Geografia e Estatística (IBGE), Luís Correia- PI possui uma população de pouco mais de 30 mil habitantes, constituída de zona rural e urbana. Do início ao final do Projeto, o município não foi tão afetado pela pandemia, todavia, partir do final de 2020 até meados do mês de junho de 2021, o mesmo foi atingido fortemente. Passando de 605 casos confirmados no último boletim epidemiológico registrado em 28 de dezembro de 2020 para 1359 casos só em 2021.

Foram mais de 400 kits com materiais de proteção angariados pelo projeto, sete diferente bairros foram visitados, mais de trinta cartazes foram espalhados, com o objetivo de pontuar os principais erros e acertos no combate ao vírus e mais de 380 pessoas receberam informações de forma remota através da rede social Instagram.

\section{Considerações Finais}

A educação em saúde é uma ferramenta fundamental para a saúde pública e torna-se protagonista na execução da proposta, pois procura definir estratégias de controle, prevenção e promoção a saúde que são cruciais para a evolução da saúde de um local. O projeto proporcionou conhecer, mesmo com um número de limitado de pessoas, o estilo de vida, as condições socioeconômicas, o perfil e reconhecer os possíveis motivos que levaram ao aumento da taxa de casos e descobrir essas informações possibilita criar um caminho que deve ser trilhado, medidas que podem ser tomadas, eliminar erros e provocar acertos. Logo, destaca-se a importância de realizar pesquisas de caráter comunitário para que diferentes análises observacionais consigam contribuir em prol do bem comum.

Ademais, os trabalhos de relato de experiência são importantes para o meio acadêmico, pois visa conhecer uma realidade através da prática. Permite oferecer e motivar ações semelhantes, talvez com resultados diferentes, por isso vale ressaltar que a capacitação desses realizadores seja efetivada, para que os objetivos sejam de fato alcançados.

\section{Agradecimentos}

Ao suporte financeiro ofertado pelo Edital 07/20-Covid-19 da Universidade Federal do Delta do Parnaíba - UFDPar.

\section{Referências}

Nogueira, A.L. et al. (2020). Artigo aponta subnotificação de casos de Covid-19 em Santa Catarina. UFSC. https://noticias.ufsc.br/2020/05/artigo-apontasubnotificacao-de-casos-de-covid-19-em-santa-catarina/.

Zanotelli, C. L., Dota, E. M. (2020). A questão da desigualdade territorial municipal no Espírito Santo face à pandemia do coronavírus e a importância da existência de um Estado de bem estar social em defesa da sociedade. Revista brasileira de geografia econômica- Espaço e Economia. (17). https://doi.org/10.4000/espacoeconomia.10207.

Sousa Junior, J.H. et al. (2020) Da Desinformação ao Caos: uma análise das Fake News frente à pandemia de Coronavírus (COVID-19) no Brasil. Cadernos de Prospecção - Salvador, 13(2), Edição Especial, 331-346.

Silva, A. A. M. (2020). Sobre a possibilidade de interrupção da epidemia pelo coronavírus (COVID-19) com base nas melhores evidências científicas disponíveis. Rev BRAS EPIDEMIOL. 23: E200021.

Brasil. (2020). Coronavírus. Ministério da Saúde. https://www.coronavirus.saude. gov.br/. 
Research, Society and Development, v. 10, n. 13, e59101320838, 2021

(CC BY 4.0) | ISSN 2525-3409 | DOI: http://dx.doi.org/10.33448/rsd-v10i13.20838

Gomes, R., Nascimento, E., F., \& Araújo, F. C. (2007). Por que os homens buscam menos os serviços de saúde do que as mulheres? As explicações de homens com baixa escolaridade e homens com ensino superior. Cadernos de Saúde Pública [online]. 23(3), 565-574. https://doi.org/10.1590/S0102311 X2007000300015.

Natividade, M. S. et al. (2020). Distanciamento social e condições de vida na pandemia COVID-19 em Salvador-Bahia, Brasil. Ciência \& Saúde Coletiva, 25(9),3385-3392.

Estrela, F. M. et al. (2020). Pandemia da Covid 19: refletindo as vulnerabilidades a luz do gênero, raça e classe. Ciência \& Saúde Coletiva [online]. 25(9), 3431-3436. https://doi.org/10.1590/1413-81232020259.14052020.

Cavalcante, B. L. L. \& Lima, U. T. S. (2012). Relato de experiência de uma estudante de Enfermagem em um consultório especializado em tratamento de feridas. J Nurs Health, Pelotas (RS). 1(2), 94-103.

Estrela, C. (2018). Metodologia Científica: Ciência, Ensino, Pesquisa. Editora Artes Médicas.

Calmon, T. V. L. As condições objetivas para o enfrentamento ao COVID-19: abismo social brasileiro, o racismo, e as perspectivas de desenvolvimento social como determinantes. Fórum Democracia, Políticas Públicas \& COVID-19. Revista NAU Social. 11(20), 131 - 136.

Esteves, P. J.(2020) Coronavírus, Rev. Ciência Elem., V8(03):038. doi.org/10.24927/rce2020.038

OPAS. (2020). COVID-19 (doença causada pelo novo coronavírus). Folha informativa, OPAS / OMS - Brasil.

Senhoras, E. M. Coronavírus e Educação: análise dos impactos assimétricos. Boletim de Conjuntura/ BOCA. Ano II. 2(5), 128-136.

Kahn, J.S. \& Mcintosh K., History and Recent Advances in Coronavirus Discovery. The Pediatric Infectious Disease Journal, $24,223-227$.

Lu, R., Zhao, X., Li, J., et al. (2020) Genomic characterisation and epidemiology of 2019 novel coronavirus: implications for virus origins and receptor binding. Lancet. 395(10224), 565- 574.

Chan, J. F., Lau, S. K. \& Woo, P. C. (2013). The emerging novel Middle East respiratory syndrome coronavirus: the "knowns" and "unknowns". J Formos Med Assoc. 112(7), 372- 381.

He, F., Deng, Y., Li, W. (2020). Coronavirus disease 2019: What we know?. J Med Virol. 92, 719-725.

G1. Mapa do coronavírus no Brasil. https:// especiais.g1.globo.com/bemestar/coronavirus/mapa-coronavirus/?_ga=2.172053216.2111506115.15850476281221903934.1585047625 .

Buss, P. M. \& Pellegrini Filho, A. (2007). A saúde e seus determinantes sociais. Physis. 17(1), 77-93.

WHO. (2021). Infection prevention and control during health care when COVID-19 is suspected. World Health Organization (WHO). https://www.who.int/publications-detail/infection-prevention-and-control-during-heal h-care-when-novel-coronavirus-(ncov)- infection-is-suspected20200125. 